\title{
Influence of tempering conditions on shot-peened tool steel components in-depth residual stress profiles
}

\author{
D. Cecchin ${ }^{1}$, E. Kobza ${ }^{1,2}$, M. Cazzolli ${ }^{1}$, C. L. Azanza Ricardo ${ }^{1, a}$, M. D'Incau ${ }^{1}$, \\ M. Bandini ${ }^{2}$, and P. Scardi ${ }^{1}$
}

${ }^{1}$ Departement of Civil, Enviromental and Mechanical Engineering, University of Trento, via Mesiano 77,38123, Italy

${ }^{2}$ Department of High Technology Physics in Mechanical Engineering, Tomsk Polytechnic University, Tomsk, Russia

\author{
${ }^{3}$ Peen Service s.r.l., via A. Pollastri 7, 40138 Bologna \\ acCristy.Azanza@ing.unitn.it
}

Keywords: tool steel, in-depth profile, dislocation density, RSA, XRD.

\begin{abstract}
Tool steel (X155CrVMo121KU in the following UK15) samples were analyzed to determine the in-depth residual stress profile and to study modifications in the microstructure, induced by a shot-peening treatment. The influence of different tempering temperatures was studied. Residual stress and dislocation density profiles were measured using standard laboratory X-ray diffraction (XRD) residual stress analysis with progressive chemical layer removal. Dislocation density profiles where obtained using a Whole Powder Pattern Modeling (WPPM) procedure.
\end{abstract}

\section{Introduction}

Shot peening is a mechanical surface treatment of metallic materials, intended to create a compressive residual stress state near the surface of the workpieces, and to modify the microstructure, the mechanical properties and behavior of the treated component. This residual stress state is mostly beneficial against fatigue $[1,2,3]$ but also against other damaging processes such as stress corrosion, cracking and wear [4].

The application of this kind of treatment to a tool steel is not straightforwardly aimed to the production of tools of higher performances, even though it is already reported in literature as one of the best surface treatments for improving the fatigue life of pieces with already good performance. Actually it's also related to other applications of this kind of steel, that is used where high strength is required while keeping small sections, such has rolling elements separators in ball bearings or in rotatory speed reducers. In this sense the residual stress field induced by the treatment is not important only in terms of the surface residual stresses, but becomes important to assess the complete stress gradient and, more generally, the whole response of the material. The possibility of achieving a real improvement in fatigue life of materials is strongly conditioned by the use of the correct process parameters, so that the best compromise is obtained between intensity and extension of the compressive field, taking also into account all effects related to the extensive work-hardening due to the peening process.

The aim of the present work is to correlate the influence of standard tempering conditions, often used in the manufacturing process of this type of tool steel, with the main microstructural properties of the pieces as well as with the residual stress profile induced by the shot-peening surface treatment.

\section{Experimental}

Shot-peening treatment was performed with an air blast machine, using $\mathrm{Z} 150$ ceramic shots. ( 70\% $\mathrm{ZrO}_{2}$ and $30 \% \mathrm{SiO}_{2}$ ), with an average diameter of $150 \mu \mathrm{m}$. The use of ceramic shots prevented from any risk of surface contamination and the small dimensions of the chosen shots assures a proper surface finishing. Specimens were $24 \mathrm{~mm} \times 24 \mathrm{~mm} \times 15 \mathrm{~mm}$ blocks of UK15, a Cr-C steel (see Table 1 for 
Table 1: UK15 tool steel composition (supplied by manufacturer Cogne)

\begin{tabular}{ccccccc}
\hline $\mathrm{C}$ & $\mathrm{Si}$ & $\mathrm{Mn}$ & $\mathrm{Cr}$ & $\mathrm{Mo}$ & $\mathrm{V}$ & $\mathrm{Fe}$ \\
\hline 1.55 & 0.30 & 0.30 & 12.0 & 0.80 & 0.90 & res. \\
\hline
\end{tabular}
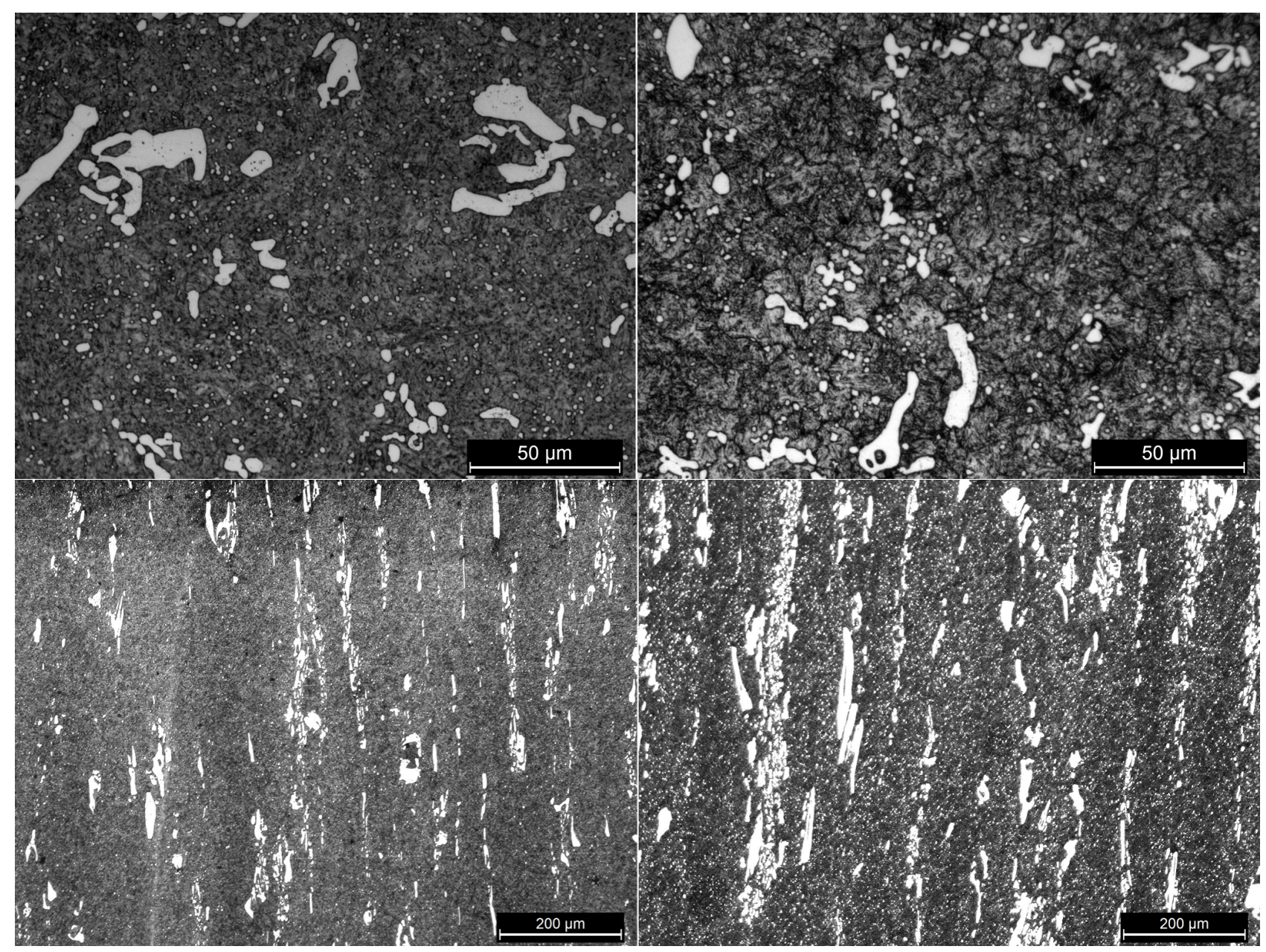

Fig. 1: Micrographies of tempered UK15 samples for 2 hours at $150^{\circ} \mathrm{C}$ (left) and at $550^{\circ} \mathrm{C}$ (right). Upper images (500x) correspond to sample's surface while lower ones $(100 \mathrm{x})$ to the cross-section of the specimens.

composition). One sample was used as reference (as supplied) and shot-peened while three tempering conditions were tested in this work. Samples were pre-heated at $600^{\circ} \mathrm{C}$ then heated up to $1020^{\circ} \mathrm{C}$ and soaked at this temperature for 10 minutes, finally they were quenched in room-temperature oil. After cooling in air to room-temperature they were tempered in three different ways, soaking one sample for 2 hours at: $150^{\circ} \mathrm{C}$ in order to obtain the higher hardness, $300^{\circ} \mathrm{C}$ the highest impact stress and $550^{\circ} \mathrm{C}$ which is in the region of medium hardness for this material. Samples were all then shot-peened (with a Norblast machine) with the same Almen intensity (12.7A) at full coverage [5].

XRD data for residual stress determination was collected with a Philips X'Pert MRD diffractometer, using a configuration specifically designed for this purpose. Measurements were performed on the $\mathrm{Fe}$ (211) reflection, using $\mathrm{CoK} \alpha$ radiation and $\mathrm{X}$-ray elastic constants for a high chromium content steel $\left(\frac{1}{2} \mathrm{~S}_{2}=5.671 / \mathrm{TPa}\right)$ [6]. At each layer removal step (starting with the surface), data was collected with both positive and negative $\psi$-tilts for two in-plane orientations $\left(\phi=0^{\circ}, 90^{\circ}\right)$ [7]. Microstructural data was collected $\mathrm{CuK} \alpha$ radiation using a standard Bragg-Brentano geometry with a high-resolution Rigaku PMG-VH diffractometer while data was analyzed following the WPPM approach using the PM2K software [8]. 




Fig. 2: In-depth residual stress profile for the tool steel samples. The inset shows an example of a $2 \theta-\psi$ scan.

\section{Results and Discussion}

In Fig. 1 some micrograph of the microstructure of the treated samples are shown: samples where polished down to mirror finishing with $3 \mu \mathrm{m}$ diamond paste, then etched with a solution which had also to color the martensitic phase in order to highlight the martensite plates. Such an analysis is appropriate since assessing the microstructural features can give more accurate information on the effect of the heat treatment in this specific case. In this work this is of utmost importance since the effect of the treatment is strongly related to the response of the material. What is expected in this case is a small effect of the tempering at lower temperature [9], limited to distension of the martensitic structure. Increasing the strength of this treatment a progressive reprecipitation and coalescence of carbides takes place, until at the highest temperature at which also some annealing starts. In fact in Fig. 1 (left) a micrograph of the sample treated at lower tempering temperature is shown, where is possible to see a microstructure composed of a tempered martensite matrix (plates edges are smoothed) with carbides that we can divide in two groups: primary carbides, present since the solidification with characteristic dimensions of some tens of microns, then secondary carbides (precipitated during heat treatments) which have more equiaxed shape and dimensions in the order of some microns. In Fig. 1 (right), where the sample tempered at higher temperature is shown, we can instead see how grain boundaries have developed and that secondary carbides have decreased in number but got bigger in size. The morphology of primary carbides is almost not influenced by the heat treatments applied within this study, since they descend from solidification. The characteristic preferential orientation of the primary carbides created due to the starting material manufacturing process (cylinders extracted from a slice of a forged bar) can be observed in the respective lower images. This procedure is mainly performed in order to break the ledeburitic microstructure of solidification. Nevertheless, the distribution of primary carbides is homogeneous and not continuous, and therefore the steel is of good quality from this point of view.

Results for the in-depth residual stress profiles are shown in Fig. 2. It is important to point out that as all samples were shot-peened with the same Almen intensity and coverage, different responses of the material are directly correlated with the corresponding tempering conditions. From the latter plot it is possible to notice that the larger extension of the compressive stress profile can be found in the nottempered sample as well as in the higher temperature treatment; while for the lower and intermediate temperature a well defined profile with a maximum of compressive stress in the near surface region can be found. 

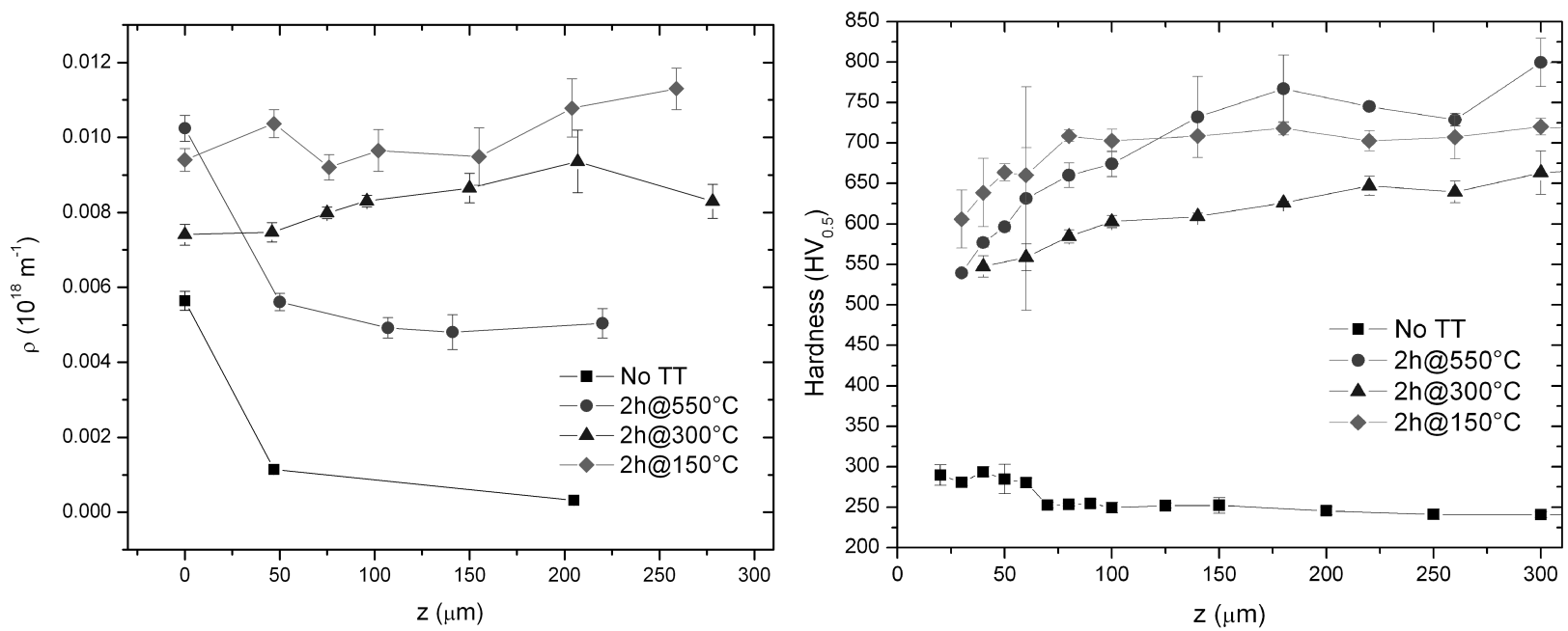

Fig. 3: Dislocation density profile (left) and microhardness profile (right) for the tool steel samples.

Table 2: HRC hardness measured for all the tempering conditions.

\begin{tabular}{ccccc}
\hline Temper & No Temper & $2 \mathrm{~h} @ 150^{\circ} \mathrm{C}$ & $2 \mathrm{~h} @ 300^{\circ} \mathrm{C}$ & $2 \mathrm{~h} @ 550^{\circ} \mathrm{C}$ \\
\hline $\mathrm{HRC}$ (section) & 14 & 56 & 52 & 57 \\
$\mathrm{HRC}$ (surface) & 18 & 53 & 58 & 55 \\
\hline
\end{tabular}

If we compare previous results with the dislocation density profile (Fig. 3 (left)) it can be seen that for the first kind of behavior (in which an extended region of compressive stress is found) a maximum of dislocation density is observed in the surface, while in the second case dislocation density remains almost constant in the measured range, having a small decrease near the surface. The former is actually the expected behavior of the dislocation density profile after performing a shot-peening treatment as a direct consequence of the plastic deformation induced by the shots in the near surface region. Nevertheless the high dislocation density obtained in the samples tempered at $150^{\circ} \mathrm{C}$ and $300^{\circ} \mathrm{C}$ becomes also a good indicator of the treatment quality increasing the material hardness avoiding further dislocation movement [10].

Since dislocation density is commonly interpreted as measurement of plastic deformation in metallic material, one would expect that maximum amount of deformation has been reached on the surface. In fact this is verified for softer materials, as the "as supplied" and the strongly annealed in this study. To explain the behavior of less annealed ones, the theory of the development of the residual stress field has been studied [11]: the key point has been identified in the fact that materials presenting the maximum of stress under the surface undergo reverse yielding. When a shot hits the sample, the pressure deforms plastically its surface, after the rebound the core (which remained undeformed or at most elastically deformed) puts the surface in a state of compressive stress, which can lead once more to plastic deformation. This effect can be explained by the remobilization or even the annihilation of piled-up dislocations [12]. So the lower amount of dislocations on the surface is not due to a lack in effectiveness of the treatment, in terms of low deformation or cold work given by the impact of the shots, but to the response of the material to the mechanics of the process.

Fig. 3 (right) shows the corresponding profile of measured microhardness for all samples, where it is possible to notice a slightly lower average microhardness in the near surface region, exactly where the compressive residual stress profile is confined. It is important to notice that the reported values are taken as mean values of several "blind" measurements in order to take into account the possible variability of the single measured point due to the presence of large primary carbides that locally increases the microhardness. Macroscopic hardness (HRC) was also measured after shot-peening, both, in the surface and in the sample's section (see Table 2), leading to no strong differences in all 




Fig. 4: Cross-section in near-surface region (500x) of the UK15 samples tempered for 2 hours at $150^{\circ} \mathrm{C}$ (left) and at $550^{\circ} \mathrm{C}$ (right).

cases (excluding the not tempered one). This result also confirms the proper extension of the tempering treatment giving almost the same HRC hardness in the surface and in the core of the samples.

In order to have a better understanding of the different behavior of the low temperature tempered sample and the high temperature one, Fig. 4 shows the respective micrographs of the section of the near surface region. It is possible to note how in the more annealed sample (right) the region influenced by the shot-peening treatment is well defined and primary carbides are clearly broken as consequence of the incoming shots; while for the lower temperature tempering condition (left) the structure remains intact. The last result, together with the large homogeneity of the obtained samples (same microstructure as the one shown in Fig. 1 and in all observed regions not shown here) is a good indicator of material quality and stability. It is important to stress out that even if in the present work only one image is shown for each case, the same microstructure extends in the overall analyzed surface and/or sections.

\section{Conclusions}

Well defined compressive residual stress profiles were successfully obtained in the near surface region of tool steel samples. Different standard tempering conditions were tested and the one performed at lower temperature resulted in the most promising one, leading to a homogeneous material (avoiding the reprecipitation and coalescence of carbides thus keeping the homogeneous distribution of the primary carbides) with an appropriate hardness and a high dislocation density profile. The present work shows the successful combination of different approaches (XRD for the determination of the residual stress and dislocation in-depth profiles, microhardness as well as surface and cross-section metallographic analysis); applied to a case in which a single characterization technique may fail. Therefore a better understanding of the influence of the shot-peening surface treatment in tool steels subjected to different tempering conditions was achieved. 


\section{References}

[1] G.H. Farrahi and H. Ghadbeigi: J. Mater. Process. Tech. Vol 174 (1-3) (2006), p. 318-324.

[2] C.L. Azanza Ricardo, G. Degan, M. Bandini and P. Scardi: Mater. Sci. Forum Vol. 638-642 (2010), p. 2464-2469.

[3] M. Benedetti, V. Fontanari, P. Scardi, C.L. Azanza Ricardo and M. Bandini: Int. J. Fatigue Vol. 31(8-9) (2009), p. 1225-1236.

[4] Y. Harada and K. Fukaura: Int. J. Mod. Phys. B Vol 22 (31n32) (2008), p. 6094-6099.

[5] SAE: SAE Manual on Shot Peening - SAE J808a, Society of Automotive Engineers Inc, USA (1967).

[6] B.D. Cullity: Elements of X-ray Diffraction, 2nd Edition, Addison-Wesley (1978).

[7] SAE: HS-784, Residual Stress Measurement by X-Ray Diffraction, Society of Automotive Engineers Inc, USA (2003).

[8] M. Leoni, T. Confente and P. Scardi: Z. Kristallogr. Supp. Vol. 23 (2006), p. 249254.

[9] D.A. Porter and K.E. Easterling: Phase Transformations in Metals and Alloys, Third Edition, London; New York: Chapman and Hall (1992).

[10] N. Mebarki, D. Delagnes, P. Lamesle, F. Delmas, C. Levaillant: Mat. Sci. Eng. A Vol 387-389 (2004), p. 171-175.

[11] B. Bhuvaraghan and S. Srinivasan: CMES-Comp. Model Eng. Vol. 57(2) (2010), p. 137158.

[12] W. F. Hosford. Residual stresses in: Mechanical behaviour of materials, chapter 18. Cambridge University Press (2000). 